\title{
The New Role of Cytomorphology from Ultrasound-Guided Fine Needle Aspiration Cytology in Evaluating the Status of Prognostic Factors Including Estrogen Receptor, Progesterone Receptor and HER2 in Breast Cancer
}

\section{Yunzhu Li}

Sichuan Cancer Hospital and Research Institute: Sichuan Cancer Hospital and Institute Jiayu Li

Sichuan Cancer Hospital and Research Institute: Sichuan Cancer Hospital and Institute

Shijun Jia

Sichuan Cancer Hospital and Research Institute: Sichuan Cancer Hospital and Institute

Yuqi Yao

Sichuan Cancer Hospital and Research Institute: Sichuan Cancer Hospital and Institute

Yehan Zhou

Sichuan Cancer Hospital and Research Institute: Sichuan Cancer Hospital and Institute

Yang Liu ( $\square$ liuyang_sccancer@sina.com )

Sichuan Cancer Hospital and Research Institute: Sichuan Cancer Hospital and Institute https://orcid.org/0000-0002-23719910

\section{Research Article}

Keywords: Cytomorphology, ER, PR, HER2, Breast carcer, Scoring system

Posted Date: February 26th, 2021

DOI: https://doi.org/10.21203/rs.3.rs-265497/v1

License: @) (i) This work is licensed under a Creative Commons Attribution 4.0 International License. Read Full License 


\section{Abstract}

Purpose It is well established that estrogen receptor (ER), progesterone receptor (PR) and human epidermal growth factor receptor (HER2) have therapeutic implications cand could be regarded as prognostic factors in breast cancer. Ultrasoundguided fine needle aspiration cytology (FNAC) has revolutionized the management of cancers, providing less invasive and quick diagnostic method. There are hardly studies on the correlation between cytomorphology and three prognostic markers.

Methods We retrospectively analyzed the immunohistochemistry and fluorescence in situ hybridization of axillary lymph node specimen from 252 patients, who have been diagnosed as breast cancer at Sichuan Cancer Hospital. Morphologic features of cytology sections were scored. The relationship between cytological features and three markers were analyzed. Based on this, we developed a new system to predict the status of markers.

Results The results indicated that some cytological parameters, especially the features of nucleoli, were distinctively related to the makers' expression. In the new scoring system, a cutoff of 12.5 provided a statistical discrimination for cytological grading. Meanwhile, it was associated with higher sensitivity for evaluating the ER and PR status ( $94 \%$ and $86 \%$, respectively), but a lower sensitivity for HER2 status (76\%).

Conclusions We concluded that cytomorphological features are associated with three prognostic factors. The HR+ tumors showed scattered micro-nucleoli, while HER2-amplication tumors demonstrated centered macro-nucleoli. Based on this, we summarized six parameters to form a new scoring system to predict the status of three factors. This may help us to broaden the application of breast cancer cytology.

\section{Introduction}

Breast cancer is one of the most common malignant diseases and remains the leading cause of cancer-related death in women [1]. Timely diagnosis is critical. Among the diagnostic and prognostic factors, estrogen receptor (ER), progesterone receptor (PR) and human epidermal growth factor receptor (HER2) play an important role in guiding treatments. Hormone receptor (HR), including ER and PR can regulate the growth and differentiation of normal breast epithelial cells, as well as tumor cells [2]. Patients with positive ER and PR can benefit from hormonal therapies [3]. HER2 is a proto-oncogene, which can regulate cellular functions, such as proliferation and apoptosis. HER2-positive breast cancer is sensitive to targeted therapies, such as trastuzumab, lapatinib and pertuzumab [4].In clinical practice, it often takes 24 to 48 hours to get the results of immunohistochemistry and fluorescence in situ hybridization (FISH), after the biopsy or surgical resection.

Unlike histology, cytology focuses on analyzing cell structures to diagnose disease. Compared with needle core biopsy, ultrasound-guided fine needle aspiration cytology (FNAC) has gained wide-spread acceptance as a rapid, simple and less invasive diagnostic method of breast mass or axillary lymph node [5]. However, the application of FNAC in breast cancer is limited to categorizing the tumor cells from axillary lymph node sample. The cytomorphological parameters from FNAC are merely used as a tool for cytological grading [6]. Its application needs to be expanded urgently. International consensus conferences on breast cancer have proposed to include prognostic factors in cytology reports [7].

It is well-known, histologically, the evaluation of the cytological morphology of breast cancer mainly depends on the ElstonEllis modification of Scarff-Bloom-Richardson grading system, in which the tubule formation is one of the critical features. In contrast, cytologically, the tubule formation cannot be accurately assessed on cytological smears, while the cytological features can be better observed. In the absence of formaldehyde fixation and section, the morphology observation is closer to the true state of cells. The genetic expression changes of ER, PR and HER2 largely depend on transcript levels and the expression of protein. It may also lead to cytomorphological changes [8]. Thus, discovering the distinctive cytological features of breast cancer cells may help pathologists enrich their understanding of the cases with different status of prognostic factors. To our best knowledge, few studies on the correlation between cytomorphological features of breast 
cancer and the expression of the prognostic factors are available. Previous studies mainly focused on the application of cell morphology for cytological grading, such as the widely-used Robinson's grading system and Taniguchi system [9-10].

In this study, we found that some cytological features were related to the expression of ER, PR and HER2, which launched the step stone for us to evaluate various parameters, aiming to find indicators related to prognostic factors. Moreover, the selected parameters were used to form a new evaluation system to provide more information for the cytological evaluation of breast cancer.

\section{Materials And Methods}

\section{Case Selection}

The study cohort comprised 252 female patients with invasive breast cancer, who were diagnosed at Sichuan Cancer Hospital \& Institute between September 2018 and August 2019.

The study was approved by ethics committee of Sichuan Cancer Hospital.

The median age was 50-years old. All the patients were performed with ultrasound-guided FNAC of axillary lymph node before a core needle biopsy or surgical treatment. The specimens were stained with immunohistochemistry for ER, PR and FISH for HER2. Data of clinicopathological parameters, including age, tumor size, histological grade, histological subtype, and nodal involvement, were obtained from medical records.

Evaluation of cytomorphological features

Using a 20-gauge, FNAC was performed with the guidance of ultrasound. The cytology smears were fixed in 95\% alcohol, then performed with routine hematoxylin-eosin (HE) staining. According to the Robinson's and Taniguchi's grading system, two experienced pathologists, who were blinded to cytology diagnosis and histopathology diagnosis, evaluated eight standard cytological parameters independently. The cytology smears included dissociation, cell size, nuclear pleomorphism, nucleoli, nuclear margin, nuclear/cytoplasmic ratio, density of chromatin and chromatin granularity $[9,11]$. For each sample, the minimal cellularity criteria were 6 groups of at least 10 cells. We also analyzed three new parameters according to our observation: a) nucleolar size: micro, medium, macro. b) nucleolar location: scattered, centered. c) nucleolar number: one, two-three, more than three.

Immunohistochemical analysis

$\mathrm{HE}$ and immunohistochemistry of metastatic axillary lymph node from surgical resection were reviewed by two pathologists. The rabbit monoclonal antibodies included anti-ER (SP1, Maxim, Fuzhou, China), anti-PR (SP2, Maxim), and anti-C-erbB2/HER2 (EP3, Maxim). All procedures were performed in the EnVision System by a Benchmark-ULTRA automatic immunohistochemical staining instrument (Asia-core, China). ER and PR were considered positive when there was more than $1 \%$ nuclear staining, according to the guideline of American Society of Clinical Oncology/College of America Pathologists (ASCO/CAP) $[12,13]$. HER2 expression was considered negative (HER2-) with scores of 0 and 1 (no staining or $<10 \%$ membrane staining of tumor cells) and positive (HER2+) with score 3+ (strong complete membrane staining in $>10 \%$ tumor cells). Cases with immunohistochemistry $2+$ were considered positive only if FISH proved to be amplified.

Fluorescence in situ hybridization (FISH)

The test of HER2 was performed by using PanthVysion kit (GSP, LBP, Guangzhou, China). According to the guidelines of 2007 ASCO/CAP, the evaluation of HER2-amplification was based on the ratio of HER2 to centromere 17 copy number [14]. A case was considered as gene amplified for the HER2/CEP17 ratio of 2.2, negative with the ratio less than 1.8 and equivocal with ratio less than 2.2 but more than 1.8 . The equivocal cases were not selected in our cohort.

\section{Statistical Analysis}


SPSS (version 22) was used to analyze the data. The relationship between cytological parameters and the status of ER, PR, HER2 was evaluated, using the Mann-Whitney U test, chi-square test and Fisher's exact test.

The scoring system was based on the regression model by valuating the predictive cytological parameters, according to the magnitude of each parameter estimate.

P-value $<0.05$ was considered statistically different.

\section{Results}

Clinicopathologic characteristics of invasive breast cancer

The clinical features of patients were shown in Table 1. Most cases (78.5\%) were invasive carcinoma of no special type. Mean tumor size was $33 \mathrm{~mm}$ ranging from 6 to $150 \mathrm{~mm}$. As for histologic grade, $65.9 \%$ was high. In addition, 143 cases (56.7\%) were classified as T2. Results of ER, PR and HER2 expression were also summarized as follows: $58.7 \%$ were ERpositive, 53.2\% were PR-positive and 46\% were HER2-overexpression, respectively. Specially, 85\% ER positive cases had PR expression. 
Table 1

Clinicopathologic features of all patients suffering from breast carcinoma $(\mathrm{N}=252)$

\begin{tabular}{|c|c|}
\hline Clinicopathologic parameters & Number of sample (\%) \\
\hline \multicolumn{2}{|c|}{ Age (years) (mean 50, median 49, range 25-76) } \\
\hline$<40$ & $23(9.1 \%)$ \\
\hline 40 to 50 & $124(49.2 \%)$ \\
\hline$>50$ & $105(41.7 \%)$ \\
\hline \multicolumn{2}{|c|}{ Tumor size $(\mathrm{mm})$ (mean 33, median 30, range 6-150) } \\
\hline$<20$ & $41(16.3 \%)$ \\
\hline 20 to 50 & $174(69.0 \%)$ \\
\hline$>50$ & $19(7.5 \%)$ \\
\hline Unknown & $18(7.1 \%)$ \\
\hline \multicolumn{2}{|l|}{ Histologic grade } \\
\hline 1 & $6(2.4 \%)$ \\
\hline 2 & $73(29.0 \%)$ \\
\hline 3 & $166(65.9 \%)$ \\
\hline Not assessable & $7(2.8 \%)$ \\
\hline \multicolumn{2}{|c|}{ Expression of ER, PR and HER2 (Positive/Negative) } \\
\hline $\mathrm{ER}(+/-)$ & $148 / 104(58.7 \% / 41.3 \%)$ \\
\hline $\mathrm{PR}(+/-)$ & $134 / 118(53.2 \% / 46.8 \%)$ \\
\hline HER2(+/-) & $116 / 136(46.0 \% / 54.0 \%)$ \\
\hline \multicolumn{2}{|l|}{ Histologic subtype } \\
\hline IDC (NOS) & $198(78.5 \%)$ \\
\hline ILC & $24(9.6 \%)$ \\
\hline Other invasive breast carcinomas & $25(9.9 \%)$ \\
\hline Unknown & $5(2.0 \%)$ \\
\hline \multicolumn{2}{|l|}{ Lymph node status } \\
\hline Metastasis in 1 to 3 lymph nodes & $159(70.6 \%)$ \\
\hline Metastasis in 4 or more lymph nodes & $60(23.8 \%)$ \\
\hline Not available & $14(5.6 \%)$ \\
\hline \multicolumn{2}{|l|}{ Stage } \\
\hline $\mathrm{T} 1$ & $35(13.9 \%)$ \\
\hline $\mathrm{T} 2$ & $143(56.7 \%)$ \\
\hline T3 & $41(16.3 \%)$ \\
\hline
\end{tabular}




\begin{tabular}{|ll|}
\hline Clinicopathologic parameters & Number of sample (\%) \\
\hline T4 & $20(8.4 \%)$ \\
\hline Unknown & $13(5.2 \%)$ \\
\hline
\end{tabular}

Cytomorphological features with ER+, PR + and HER2-overexpression tumors

The nuclei of ER + and/or PR + tumors (Fig. 1a) was smaller than HER2-overexpression tumors (Fig. 1b). In ER + and/or PR + tumor cells (Fig. 1c), the nucleoli accounted for about $1 / 5$ of the nuclear diameter and was dispersed or clinging to the nuclear membrane. In HER2-overexpression tumor cells (Fig. 1d), the nucleoli accounted for about 1/3 of the nuclear diameter and was located in the center of the nuclei.

Correlation of cytomorphological features with status of ER, PR and HER2

To explore the relationship between cytological characteristics and prognostic factors, we analyzed 11 parameters. The results were summarized in Table 2. Among the eight standard parameters, dissociation and nuclear margin were from Robinson's system, and nuclear/cytoplasmic ratio and density of chromatin were from Taniguchi's system. And the three new parameters including nucleolar size, nucleolar location and nucleolar number were based on our observation. In 252 samples, ER + tumors had smaller cell than ER-tumors $(P<0.001)$. ER-tumors showed more marked pleomorphism $(P<$ $0.001)$, nucleoli $(P<0.001)$ and folds, irregular nuclear margin $(P<0.001)$ than its competitor. In addition, significant difference was observed among PR + and PR- samples. 
Table 2

Correlation between cytologic parameters (eight standard and three new parameters) and the status of ER, PR and HER2

\begin{tabular}{|c|c|c|c|c|c|c|c|c|c|}
\hline & \multicolumn{3}{|l|}{ ER } & \multicolumn{3}{|l|}{ PR } & \multicolumn{3}{|l|}{ HER2 } \\
\hline & Positive & Negative & $\begin{array}{l}\mathrm{P} \text { - } \\
\text { value }\end{array}$ & Positive & Negative & $\begin{array}{l}\mathrm{P} \text { - } \\
\text { value }\end{array}$ & Positive & Negative & $\begin{array}{l}\mathrm{P} \text { - } \\
\text { value }\end{array}$ \\
\hline Dissociation & & & 0.971 & & & 0.508 & & & 0.037 \\
\hline clusters & $34(23.0)$ & $28(26.9)$ & & $33(24.6)$ & $29(24.6)$ & & $26(22.4)$ & $36(26.5)$ & \\
\hline $\begin{array}{l}\text { single and } \\
\text { clusters }\end{array}$ & $76(51.4)$ & 45(43.3) & & $68(50.7)$ & $53(44.9)$ & & $49(42.2)$ & $72(52.9)$ & \\
\hline single & $38(25.7)$ & $31(29.8)$ & & $33(24.6)$ & $36(30.5)$ & & $41(35.3)$ & $28(20.6)$ & \\
\hline Cell size & & & $<.001$ & & & $<.001$ & & & $\begin{array}{l}<.001 \\
\end{array}$ \\
\hline $1-2 \times R B C$ & $52(35.1)$ & $7(6.7)$ & & $48(35.8)$ & $11(9.3)$ & & $12(10.3)$ & $47(34.6)$ & \\
\hline $2-4 \times R B C$ & $84(56.8)$ & $46(44.2)$ & & 71(53.0) & $59(50.0)$ & & $57(49.1)$ & 73(53.7) & \\
\hline$\geq 5 \times R B C$ & 12(8.1) & $51(49)$ & & $15(11.2)$ & $48(40.7)$ & & $47(40.5)$ & 16(11.8) & \\
\hline \multicolumn{3}{|c|}{ Nuclear pleomorphism } & $<.001$ & & & $<.001$ & & & $\dot{0} 001$ \\
\hline Uniform & $25(16.9)$ & $5(4.8)$ & & $23(17.2)$ & $7(5.9)$ & & $6(5.2)$ & $24(17.6)$ & \\
\hline Mild & 118(79.7) & $71(68.3)$ & & 104(77.6) & $85(72.0)$ & & $87(75.0)$ & $102(75.0)$ & \\
\hline Marked & 118(79.8) & $28(26.9)$ & & $7(5.2)$ & $26(22.0)$ & & 23(19.8) & $10(7.4)$ & \\
\hline Nucleoli & & & $<.001$ & & & $<.001$ & & & 0.09 \\
\hline Indistinct & $53(35.8)$ & $10(9.6)$ & & $46(34.3)$ & $17(14.4)$ & & $24(20.7)$ & $39(28.7)$ & \\
\hline Noticeable & $69(46.6)$ & $60(57.7)$ & & $65(48.5)$ & $64(54.2)$ & & $60(51.7)$ & $69(50.7)$ & \\
\hline Prominent & $26(17.6)$ & $34(32.7)$ & & $23(17.2)$ & $37(31.4)$ & & $32(27.6)$ & $28(20.6)$ & \\
\hline $\begin{array}{l}\text { Nuclear } \\
\text { margin }\end{array}$ & & & $<.001$ & & & 0.004 & & & 0.391 \\
\hline Smooth & $9(6.1)$ & $5(4.8)$ & & $9(6.7)$ & $5(4.2)$ & & $7(6.0)$ & $7(5.1)$ & \\
\hline Folds & 133(89.9) & $71(68.3)$ & & 115(85.8) & $89(75.4)$ & & $90(77.6)$ & 114(83.8) & \\
\hline Buds & $6(4.1)$ & $28(26.9)$ & & $10(7.5)$ & $24(20.3)$ & & 19(16.4) & $15(11.0)$ & \\
\hline Nuclear/cyto & lasmic ratio & & 0.507 & & & 0.844 & & & 0.517 \\
\hline$<50$ & $8(5.4)$ & $15(14.4)$ & & $8(6.0)$ & $15(12.7)$ & & $13(8.9)$ & $10(9.4)$ & \\
\hline $50-80$ & $126(85.1)$ & $74(71.2)$ & & 114(85.1) & $86(72.9)$ & & $115(78.8)$ & $85(80.2)$ & \\
\hline$>80$ & $14(9.5)$ & $15(14.4)$ & & $12(9.0)$ & $17(14.4)$ & & 18(12.3) & 11(10.4) & \\
\hline Density of ch & omatin & & 0.13 & & & 0.001 & & & 0.778 \\
\hline
\end{tabular}

a. Fisher's exact test (mico vs medium and macro). b. Fisher's exact test (medium vs macro). c. chi-square test (peripheral vs centered) and others were tested with Mann-Whitney U test.

\#: new parameters from our observation. 


\begin{tabular}{|c|c|c|c|c|c|c|c|c|c|}
\hline \multicolumn{4}{|c|}{ ER } & \multicolumn{2}{|l|}{ PR } & & \multicolumn{2}{|l|}{ HER2 } & \\
\hline Not & $44(29.7)$ & $43(41.3)$ & & $33(24.6)$ & $54(45.8)$ & & 43(37.1) & $44(32.4)$ & \\
\hline Moderately & $97(65.5)$ & $54(51.9)$ & & $93(69.4)$ & $58(49.2)$ & & $64(55.2)$ & $87(64.0)$ & \\
\hline Markedly & $7(4.7)$ & $7(6.7)$ & & $8(6.0)$ & $6(5.1)$ & & $9(7.8)$ & $5(3.7)$ & \\
\hline \multicolumn{3}{|c|}{ Chromatin granularity } & 0.853 & & & 0.214 & & & 0.443 \\
\hline Fine & $80(54.1)$ & $58(55.8)$ & & $76(56.7)$ & $62(52.5)$ & & $62(53.4)$ & $76(55.9)$ & \\
\hline $\begin{array}{l}\text { Moderately } \\
\text { granular }\end{array}$ & $35(23.6)$ & $17(16.3)$ & & $32(23.9)$ & $20(16.9)$ & & $21(18.1)$ & $31(22.8)$ & \\
\hline Coarse & $33(22.3)$ & $29(27.9)$ & & 26(19.4) & $36(30.5)$ & & $33(28.4)$ & $29(21.3)$ & \\
\hline \multicolumn{10}{|c|}{ Nucleolar size $\#$} \\
\hline Micro & 115(77.7) & $17(16.3)$ & $<0.001^{\mathrm{a}}$ & 106(79.9) & $26(22.0)$ & $<.001$ & $39(33.6)$ & $94(69.1)$ & $\hat{0} .001$ \\
\hline Medium & $31(21.0)$ & $63(60.6)$ & $\begin{array}{l}< \\
0.001^{b}\end{array}$ & 21(15.7) & $74(62.7)$ & & $62(53.4)$ & $33(24.3)$ & \\
\hline Macro & $2(0.01)$ & $24(23.1)$ & & $7(4.5)$ & 18(15.3) & & $15(12.9)$ & $9(6.6)$ & \\
\hline \multicolumn{2}{|c|}{ Nucleolar location\# } & & $\begin{array}{l}< \\
0.001^{\mathrm{c}}\end{array}$ & & & $\begin{array}{l}< \\
0.001^{c}\end{array}$ & & & $<0.001^{\mathrm{c}}$ \\
\hline Peripheral & 106(71.6) & $6(5.8)$ & & $98(73.1)$ & 14(11.9) & & $24(20.7)$ & $88(64.7)$ & \\
\hline Centered & $42(28.4)$ & $98(94.2)$ & & $36(26.9)$ & 104(88.1) & & $92(79.3)$ & $48(35.3)$ & \\
\hline \multicolumn{2}{|c|}{ Nucleolar number $\#$} & & $<.001$ & & & $<.001$ & & & $<.001$ \\
\hline$\leq 1$ & $61(41.2)$ & 97(93.3) & & $54(40.3)$ & 104(88.1) & & $94(81.0)$ & $64(47.1)$ & \\
\hline $2-3$ & $32(21.6)$ & $5(4.8)$ & & $31(23.1)$ & $6(5.1)$ & & $9(7.8)$ & $28(20.6)$ & \\
\hline$>3$ & $55(37.2)$ & $2(1.9)$ & & $49(36.6)$ & $8(6.8)$ & & $13(11.2)$ & $44(32.4)$ & \\
\hline \multicolumn{10}{|c|}{$\begin{array}{l}\text { a. Fisher's exact test (mico vs medium and macro). b. Fisher's exact test (medium vs macro). c. chi-square test } \\
\text { (peripheral vs centered) and others were tested with Mann-Whitney U test. }\end{array}$} \\
\hline
\end{tabular}

There were two cytological parameters demonstrated statistically different between HER2-overexpression and HER2samples. Larger cells and marked nuclear pleomorphism were detected in HER2 + samples $(P<0.001)$ (Fig. 1b). No significant difference was observed between positive and negative samples of the markers when we tested the cytological features, which included dissociation, nuclear/cytoplasmic ratio, density of chromatin and chromatin granularity.

Both ER + and PR + tumors showed smaller nucleolar size and less pleomorphism, compared to negative ones $(P<0.001)$. Additionally, in $106 \mathrm{ER}+$ and $98 \mathrm{PR}+$ tumors, the nucleolar location was scattered by contrast to 6 ER- samples and 14 PRsamples $(P<0.001)$. ER- or PR- tumors were more likely to show one or less nucleoli, compared with $E R+(P<0.001)$ or $P R+$ $(P<0.001)$ tumors. In contrast, HER2 + samples had bigger nucleolar size $(P<0.001)$ but less cells than HER2- samples $(P<$ 0.001). Besides, the nucleoli showed more centered in 92 (79.3\%) HER2 + than HER2- samples $(P<0.001)$.

Multivariate analysis and cytological model for cytological grading and predicting status of the three factors 
Based on our findings, we finally selected six parameters, which were significantly associated with three markers, to form a new system. Detailed standards were shown in Table 3.

Table 3

The new scoring system for predicting the status of ER, PR and HER2

\begin{tabular}{|llll|}
\hline & Score 1 & Score 2 & Score 3 \\
\hline Cell size & $<3 \times$ RBC size & $3-4 \times$ RBC size & $>4 \times$ RBC size \\
\hline Nucleoli & Indistinct & Noticeable & Prominent \\
\hline Nucleolar size & Micro & Medium & Macro \\
\hline Nucleolar location & Scattered & & Centered \\
\hline Nucleolar number & $>3$ & $2-3$ & $\leq 1$ \\
\hline Nucleolar margin & Round, smooth & Smooth & Irregular \\
\hline
\end{tabular}

We next performed a multivariate analysis to identify the cytological features which were independently associated with the expression of ER, PR and HER2 (Table 4). The results indicated that the cell size $(P<0.001)$, nucleolar size $(P=0.030)$, nucleolar location $(P=0.005)$, nucleolar number $(P=0.043)$ and nuclear margin $(P=0.043)$ were the independently associated with the expression of ER. In addition, only the cell size and nucleolar location were correlated with the status of PR and HER2.

Table 4

Multivariate logistic regression analysis for determination of the likelihood of ER, PR and HER2 status from new system's cytologic features

\begin{tabular}{|c|c|c|c|c|c|c|}
\hline & ER+ & & PR+ & & HER2+ & \\
\hline & OR $(95 \% \mathrm{Cl})$ & $\begin{array}{l}\text { P- } \\
\text { value }\end{array}$ & OR $(95 \% \mathrm{Cl})$ & $\begin{array}{l}\mathrm{P} \text { - } \\
\text { value }\end{array}$ & OR $(95 \% \mathrm{Cl})$ & $\begin{array}{l}\mathrm{P}- \\
\text { value }\end{array}$ \\
\hline Cell size & $0.237(0.122-0.460)$ & $<0.001$ & $0.469(0.277-0.791)$ & 0.005 & $\begin{array}{l}2.548(1.583- \\
4.104)\end{array}$ & $<0.001$ \\
\hline Nucleoli & $0.565(0.303-1.052)$ & 0.072 & $0.688(0.414-1.145)$ & 0.15 & $\begin{array}{l}0.992(0.638- \\
1.543)\end{array}$ & 0.992 \\
\hline Nucleolar size & $0.425(0.196-0.921)$ & 0.03 & $\begin{array}{l}0.678(0.337- \\
1.3255)\end{array}$ & 0.271 & $\begin{array}{l}0.861(0.457- \\
1.624)\end{array}$ & 0.65 \\
\hline $\begin{array}{l}\text { Nucleolar } \\
\text { location }\end{array}$ & $\begin{array}{l}6.201(1.758- \\
21.878)\end{array}$ & 0.005 & $\begin{array}{l}6.889(2.546- \\
18.638)\end{array}$ & $<0.001$ & $\begin{array}{l}0.224(0.090- \\
0.563)\end{array}$ & 0.001 \\
\hline $\begin{array}{l}\text { Nucleolar } \\
\text { number }\end{array}$ & $0.363(0.136-0.969)$ & 0.043 & $0.697(0.377-1.289)$ & 0.25 & $\begin{array}{l}1.253(0.746- \\
2.104)\end{array}$ & 0.394 \\
\hline Nuclear margin & $0.367(0.139-0.967)$ & 0.043 & $0.890(0.402-1.969)$ & 0.773 & $\begin{array}{l}0.761(0.378- \\
1.533)\end{array}$ & 0.445 \\
\hline
\end{tabular}

The cutoff value was set as 12.5, according to the multivariate analysis. The score of 12.5 or lower was also regarded as a highly possibility with the expression of ER or PR upon the Receiver Operating Characteristic (ROC) analysis. At this cutoff (Table 5), the sensitivity and specificity were $94 \%$ and $77 \%$ for detecting the ER-expression. We also verified the scoring system for the expression of PR, the sensitivity was $86 \%$ and the specificity was $78 \%$, respectively. With regard of HER2 status, the sensitivity, specificity, positive predictive value (PPV) and negative predictive value (NPV) was $76 \%, 68 \%, 67 \%$ and $77 \%$, respectively. 
Table 5

Sensitivity, specificity, PPV and NPV from the three system for assessment the status of ER, PR and HER2

\begin{tabular}{|c|c|c|c|c|c|c|c|c|c|c|c|c|}
\hline & \multicolumn{3}{|c|}{ Sensitivity } & \multicolumn{3}{|c|}{ Specificity } & \multicolumn{3}{|l|}{ PPV } & \multicolumn{3}{|l|}{ NPV } \\
\hline & $\mathrm{ER}$ & PR & HER2 & ER & PR & HER2 & $\mathrm{ER}$ & PR & HER2 & ER & PR & HER2 \\
\hline $\begin{array}{l}\text { New } \\
\text { system }\end{array}$ & 0.94 & 0.86 & 0.76 & 0.77 & 0.78 & 0.68 & 0.74 & 0.77 & 0.67 & 0.95 & 0.87 & 0.77 \\
\hline $\begin{array}{l}\text { Robinson } \\
\text { system }\end{array}$ & 0.55 & 0.57 & 0.72 & 0.76 & 0.75 & 0.55 & 0.77 & 0.72 & 0.58 & 0.54 & 0.61 & 0.7 \\
\hline $\begin{array}{l}\text { Taniguchi } \\
\text { system }\end{array}$ & 0.61 & 0.58 & 0.63 & 0.62 & 0.56 & 0.64 & 0.69 & 0.6 & 0.6 & 0.52 & 0.54 & 0.67 \\
\hline
\end{tabular}

\section{Discussion}

In our cohort analysis, the cytomorphological features were strongly associated with the expression of ER, PR and HER2. The cytomorphology of HR + tumors were opposite with the HER2-amplication tumors. HR + tumors showed scattered micronucleoli, while HER2-amplication tumors had centered macro-nucleoli and folds nuclear margins. The diametrically reserve cytological characteristics were probably due to the negative correlation between the expression of HR and HER2, which was conquered by previous studies $[15,16]$. In detail, ER is composed of nuclear receptors (ERa and ER $\beta$ ) and membranous receptor. The existing evidence demonstrated that ER $\beta$ partly counteracted the transcriptional and proliferative functions of Era $[17,18]$. ERa played a slow "genotype" regulatory to activate signaling pathways and promote cell proliferation [19], thus ER + tumors showed slow proliferation of micro-nucleoli. Furthermore, estrogen binds to receptors which located on the nuclear membrane. Their combination could regulate the expression of gene. This may explain why we observed the nucleolus is scattered but closed to the nuclear membrane. On the other hand, because of its impact on proliferation, HER2 had been proved to be related to high nuclear levels and large tumor size, as well as high risk of recurrence and metastasis [20]. This high nuclear level was in accord with macro-nucleoli in HER2-amplification samples.

Based on our findings, we combined cytological features from Robinson's, Taniguchi's grading system with our new parameters, and selected six parameters, including cell size, nucleoli, nucleolar size, nucleolar location, nucleolar number and nuclear margin, to do further analysis. According to the logistic regression analysis, our new system emphasis more on the morphology of nucleoli, such as nucleolar size $(P=0.03)$, nucleolar location $(P=0.004)$, nucleolar number of $E R(P=0.043)$. Nuclei is essential for DNA replication or transcription, and nucleoli is a major part of it. The characteristics of nucleoli has been descripted in the research conducted by Anamika Kashyap et al. It demonstrated that nucleoli features were extremely important in differentiating cytological grades of malignant tumors [21]. Because the three markers represented the proliferation of tumor cells, the changes in chromatin were not statistically different. This finding was consistent with prior study [22]. By investigating FNAC samples from patients with basal-like breast cancer (BLBC), Akashi $S$ et al found that among the cytology features of triple-negative (ER-, PR- and HER2-) breast cancer, the nuclear size and margin were distinctive, while the features of chromatin were not statistically different among their cases.

Our new scoring system was a novel one which combined cytological features with prognostic markers. Most ER + samples had a score of less than 12.5, while most HER-amplification samples had a score higher than 12.5. In our system, higher score was associated with higher grade of atypia. The atypical feature of HER2-overexpression tumors may be one of the reasons for its poor prognosis. Some studies have demonstrated that HER2 phenotype was a prognostic factor for poor outcomes [23]. Compared with HER2-overexpression tumors, ER-positive tumors have less effect on proliferation, and it's typically used to guide hormone therapy. Therefore, high atypia cytomorphology with high score more frequently appeared in HER2-overexpression tumors, rather than ER-positive tumors. In addition, by using a preclinical model of breast cancer, 
previous study demonstrated that over-expression of HER2 leads to increased cross-talk between ER and HER2 pathways, even if the mechanism of the influence between ER and HER2 remains unclear [24, 25].

At the same time, the new system has a higher sensitivity for evaluating the status of ER (94\%) and PR (86\%), but much lower for HER2 (76\%). Although the multivariate analysis shows a lower sensitivity in HER2-positive cancer, the specificity, sensitivity, positive predictive value (PPV) and negative predictive value (NPV) are better than Robinson's and Taniguchi's. In cytology, there have been at least six grading systems consist of cytomorphological features since 1980 [26-29]. In particular, Robinson's system was the most widely used, and Taniguchi's system is the only one which demonstrated the high grade was negatively correlated with ER status. On the other hand, Khan's study added the mitotic count to his system, which was not seen in most of our samples [29]. Therefore, regardless of the six systems' crucial role in cytological grading, our new system seems to be the most optimal in predicting the status of ER, PR and HER2.

It is true that our new system has good sensitivity and specificity towards ER and PR, but it also has limitations of evaluating the status of HER2. This may be owing to some genetic changes in breast cancer, such as the mutation of BRCA1/2 and TP53 [30].

\section{Conclusions}

In summary, we found that HR + tumors had scattered micro-nucleoli, while HER2-amplication tumors had centered macronucleoli and folds nuclear margins. Based on this, we summarized six parameters to form a new scoring system. Our analysis demonstrated that the new system is a novel one to predict the status of three factors. This may help us to broaden the application of breast cancer cytology.

\section{Declarations}

Acknowledgments We thank Sichuan Cancer Hospital \& Institute for clinical data supported.

Author contributions Yang $L$ designed the study, helped to write the manuscript and developed the methodology. Yunzhu $L$ collected data and wrote the manuscript. $\mathrm{JL}$ analyzed data and wrote the manuscript. YZ performed the statistical analysis. YY and SJ collected data. All the authors have reviewed and approved the final manuscript.

Funding No funding was received for this study.

\section{Compliance with ethical standards}

Conflict of interest All authors have no conflicts of interest to declare.

\section{Ethical approval}

The study was authorized by the Ethical Committee of Sichuan Cancer Hospital \& Institute.

\section{References}

1. Ferlay J, Soerjomataram I, Dikshit R et al (2015) Cancer incidence and mortality worldwide: Sources, methods and major patterns in GLOBOCAN 2012. Int J Cancer 136(5):E359-E386. https://doi.org/10.1002/ijc.29210

2. Allred DC (2010) Issues and updates: evaluating estrogen receptor-a, progesterone receptor, and HER2 in breast cancer. Mod Pathol 23(2):S52-S59. https://doi.org/10.1038/modpathol.2010.55

3. Bardou VJ, Arpino G, Elledge RM et al (2003) Progesterone receptor status significantly improves outcome prediction over estrogen receptor status alone for adjuvant endocrine therapy in two large breast cancer databases. J Clin Oncol 21(10):1973-1979. https://doi.org/10.1200/JC0.2003.09.099

Page $11 / 14$ 
4. Wolff AC, Hammond ME, Allison KH et al (2018) HER2 Testing in Breast Cancer: American Society of Clinical Oncology/College of American Pathologists Clinical Practice Guideline Focused Update Summary. J Oncol Pharm Pract 14(7):437-441. https://doi.org/10.1200/JOP.18.00206

5. Vohra P, Buelow B, Chen YY et al (2016) Estrogen receptor, progesterone receptor, and human epidermal growth factor receptor 2 expression in breast cancer FNA cell blocks and paired histologic specimens: A large retrospective study. Cancer Cytopathol 124(11):828-835. https://doi.org/10.1002/cncy.21745

6. Bansal C, Pujani M, Sharma KL et al (2014) Grading systems in the cytological diagnosis of breast cancer: a review. J Cancer Res Ther 10(4):839. https://doi.org/10.4103/0973-1482.140979

7. Cardoso F, Costa A, Norton L et al (2012) 1st International consensus guidelines for advanced breast cancer (ABC 1). Breast 21(3):242-252. https://doi.org/10.1016/j.breast.2012.03.003

8. Taniguchi E, Yang Q, Tang W et al (2000) Cytologic grading of invasive breast carcinoma. Acta Cytol 44(4):587-591. https://doi.org/10.1159/000328533

9. Bellevicine C, Sgariglia R, Migliatico I et al (2018) Different qualifiers of AUS/FLUS thyroid FNA have distinct BRAF, RAS, RET/PTC, and PAX8/PPARg alterations. Cancer Cytopatho I126(5):317. https://doi.org/10.1002/cncy.21984

10. Angelidou E, Politi E, Sotiropoulou G et al (2006) Evaluation of ER, PR, MIB-1, pS2, and nuclear grade in FNA specimens of cT1 breast carcinomas: Clinicopathological correlation. Diagn Cytopathol 34(8):547-552.

https://doi.org/10.1002/dc.20510

11. Robinson IA, McKee G, Nicholson A et al (1994) Prognostic value of cytological grading of fine-needle aspirates from breast carcinomas. Lancet 343(8903):947-949. https://doi.org/10.1016/S0140-6736(94)90066-3

12. Yi M, Huo L, Koenig KB et al (2014) Which threshold for ER positivity? A retrospective study based on 9639 patients. Ann Oncol 25(5):1004-1011. https://doi.org/10.1093/annonc/mdu053

13. Wolff AC, Hammond MEH, Hicks DG et al (2014) Recommendations for human epidermal growth factor receptor 2 testing in breast cancer: American Society of Clinical Oncology/College of American Pathologists clinical practice guideline update. Arch Pathol Lab Med 138(2):241-256. https://doi.org/10.5858/arpa.2013-0953-SA

14. Wolff AC, Hammond MEH, Schwartz JN et al (2016) American Society of Clinical Oncology/College of American Pathologists Guideline Recommendations for Human Epidermal Growth Factor Receptor 2 Testing in Breast Cancer. Arch Pathol LabMed 131(1):18-43. https://doi.org/10.1200/JC0.2006.09.2775

15. Ross JS, Muraca PJ, Jaffe D et al (1998) Multivariate analysis of prognostic factors in lymph node negative breast cancer. Eur J Cancer 34(1005):S102-S102. https://doi.org/10.1016/S0959-8049(98)80419-X

16. Eggemann H, Ignatov T, Burger E et al (2015) Moderate HER2 expression as a prognostic factor in hormone receptor positive breast cancer. Endocr Relat Cancer 22(5):725-733. https://doi.org/10.1530/ERC-15-0335

17. Horimoto Y, Hartman J, Millour J et al (2011) ERß1 represses FOXM1 expression through targeting ERa to control cell proliferation in breast cancer. Am J Surg Pathol 179(3):1148-1156. https://doi.org/10.1016/j.ajpath.2011.05.052

18. Jonsson P, Katchy A, Williams C (2014) Support of a bi-faceted role of estrogen receptor $\beta$ (ER $\beta$ ) in ERa-positive breast cancer cells. Endocr Relat Cancer 21(2):143-160. https://doi.org/10.1530/ERC-13-0444

19. Sorlie T, Tibshirani R, Parker J et al (2003) Repeated observation of breast tumor subtypes in independent gene expression data sets. Proc Natl Acad Sci U S A 100:8418-8423. https://doi.org/10.1073/pnas.0932692100

20. Ross JS, Fletcher JA (1998) The HER-2/neu oncogene in breast cancer: prognostic factor, predictive factor, and target for therapy. Stem cells 16(6):413-428. https://doi.org/10.1002/stem.160413

21. Kashyap A, Jain M, Shukla S et al (2018) Role of nuclear morphometry in breast cancer and its correlation with cytomorphological grading of breast cancer: A study of 64 cases. J Cytol 35(1):41.

https://doi.org/10.4103/JOC.JOC_237_16

22. Akashi S, Kuwabara H, Kurisu Y et al (2013) Fine-needle aspiration cytology of triple-negative basal-like breast cancer. Diagn Cytopathol 41(4):283-287. https://doi.org/10.1002/dc.21807

Page $12 / 14$ 
23. Allred DC, Swanson PE (2000) Testing for erbB-2 by immunohistochemistry in breast cancer. Am J Clin Pathol 113:171175. https://doi.org/10.1309/9x6x-1el6-5qb1-yld2

24. Massarweh S, Osborne CK, Creighton CJ et al (2008) Tamoxifen resistance in breast tumors is driven by growth factor receptor signaling with repression of classic estrogen receptor genomic function. Cancer Res 68(3):826-833. https://doi.org/10.1158/0008-5472.CAN-07-2707

25. Osborne CK, Shou J, Massarweh S et al (2005) Crosstalk between estrogen receptor and growth factor receptor pathways as a cause for endocrine therapy resistance in breast cancer. Clin Cancer Res 11:865s-8870s

26. FISHER E R (1980) Histologic grading of breast cancer. Pathol Annu 15:239-251

27. Howell LP, Gandour-Edwards R, O’Sullivan D (1994) Application of the Scarff-Bloom-Richardson tumor grading system to fine-needle aspirates of the breast. Am J Clin Pathol 101(3):262-265. https://doi.org/10.1093/ajcp/101.3.262

28. Yu GH, Cajulis RS, De Frias DVS (1998) Tumor cell (dys) cohesion as a prognostic factor in aspirate smears of breast carcinoma. Am J Clin Pathol 109(3):315-319. https://doi.org/10.1093/ajcp/109.3.315

29. Khan MZ, Haleem A, Hassani HA et al (2003) Cytopathological grading, as a predictor of histopathological grade, in ductal carcinoma (NOS) of breast, on air-dried Diff-Quik smears. Diagn Cytopathol 29(4):185-193.

https://doi.org/10.1002/dc.10285

30. Banerji S, Cibulskis K, Rangel-Escareno C et al (2012) Sequence analysis of mutations and translocations across breast cancer subtypes. Nature 486:405-409. https://doi.org/10.1038/nature11154

\section{Figures}



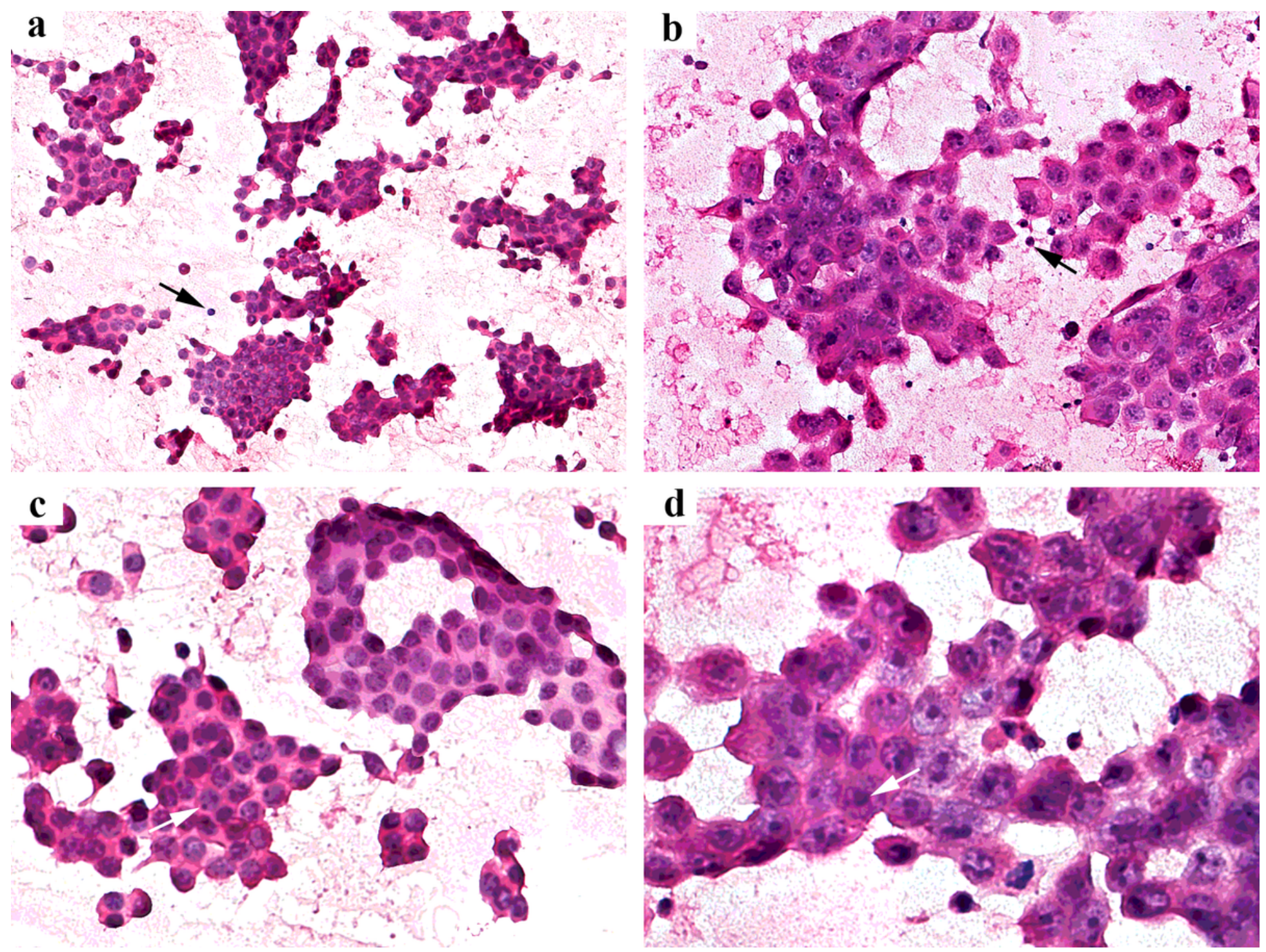

Figure 1

In figure 1, Fig. 1a $(\times 200)$ and Fig. 1b $(\times 200)$ were the same magnification (black arrow showed lymphocytes were the same size in $a$ and b). The nuclei of ER+ and/or PR+ tumors (Fig. 1a) was smaller than HER2-overexpression tumors (Fig. 1b). Fig. 1c ( $\times 400)$ and Fig. 1d ( $\times 400)$ were the same magnification. Fig. 1c: In ER+ and/or PR+ tumor cells, the nucleoli accounted for about 1/5 of the nuclear diameter and was dispersed or clinging to the nuclear membrane. Fig. 1d: In HER2-overexpression tumor cells, the nucleoli accounted for about $1 / 3$ of the nuclear diameter and was located in the center of the nuclei. 